\title{
SIMULTANEOUS OBSERVATIONS OF FREE TROPOSPHERIC SAHARAN DUST LAYERS OVER EUROPE MONITORED BY A CO-ORDINATED GROUND-BASED LIDAR NETWORK IN THE FRAME OF THE EARLINET PROJECT
}

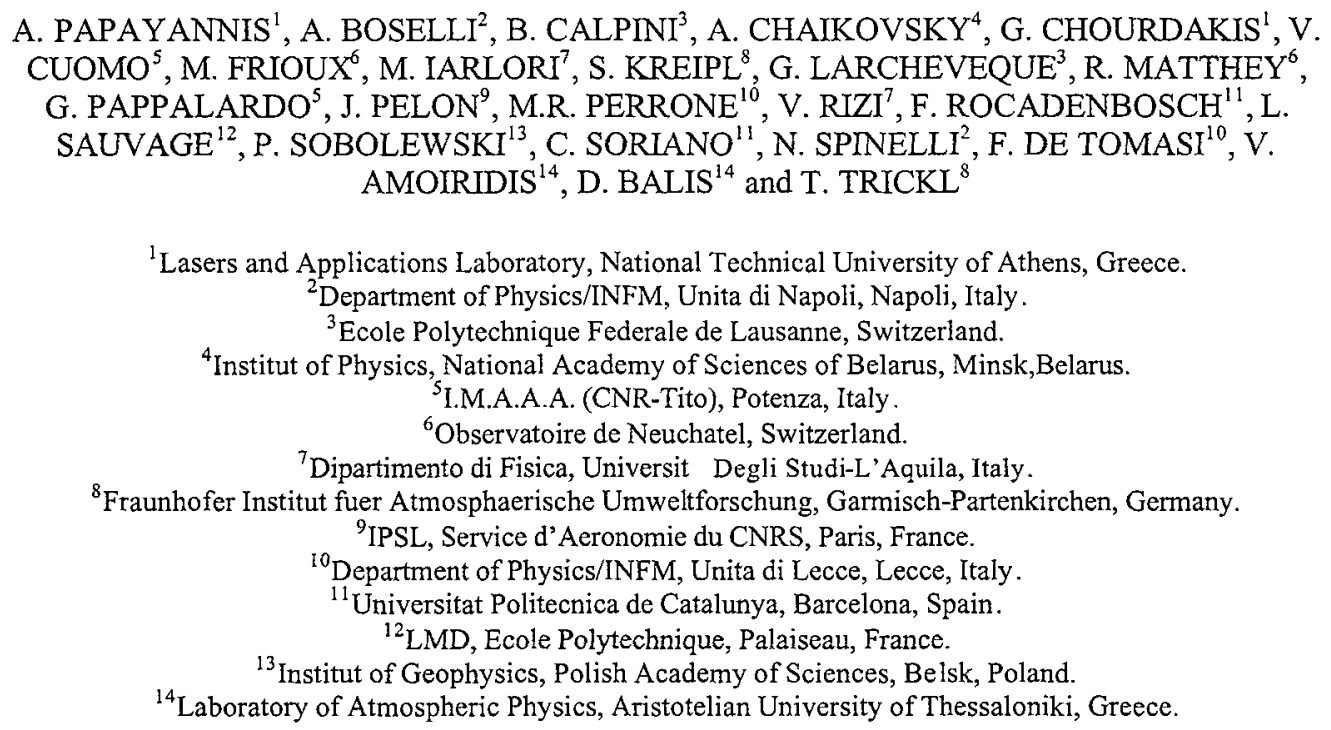

Keywords: LIDAR, ATMOSPHERIC AEROSOLS, SAHARAN DUST, CLIMATE CHANGE

\section{INTRODUCTION}

Atmospheric particles and mainly the mineral dust particles, play an important role in the earth's radiation balance and climate, by scattering and absorbing, both incoming and outcoming radiation, (Seinfeld and Pandis, 1998). Every year important quantities of desert dust from the Sahara and surrounding regions are exported to the North Atlantic Ocean and the Mediterranean Sea (Hamonou et al., 1999; Gobbi et al., 2000). Saharan dust events have been studied mainly using satellite data (Dulac et al., 1992), as a consequence, very few publications exist on the vertical distribution of desert dust particles over the Mediterranean Sea (Hamonou et al., 1999; Gobbi et al., 2000) and central Europe (Jaeger et al., 1988).

\section{METHODS}

Thirteen significant events of free tropospheric Saharan dust layers were observed over selected sites in Europe, from spring to autumn 2000, using a co-ordinated ground-based lidar network, in the frame of the EARLINET project. Ancillary observations included ground-based aerosol optical depth, spectral radiance and satellite (AVHRR, METEOSAT, TOMS) measurements. Selected cases of the spatial and temporal evolution of the vertical tropospheric aerosol backscatter profiles over the European continent were studied. The analysis of the data collected makes possible, for the first time, a simultaneous estimation of the horizontal and vertical extent of free tropospheric Saharan dust layers over Europe. Figure 1 shows two examples of Saharan dust layers observed by two lidars of the EARLINET network on August 31,2000, the first over Potenza, Italy and the second over Athens, Greece, both at 19:00 UT. The respective air-mass back trajectories, ending at the lidar observation sites (Figure 2), confirm that the source of the observed free tropospheric dust layers, is the Sahara and its surroundings regions. 

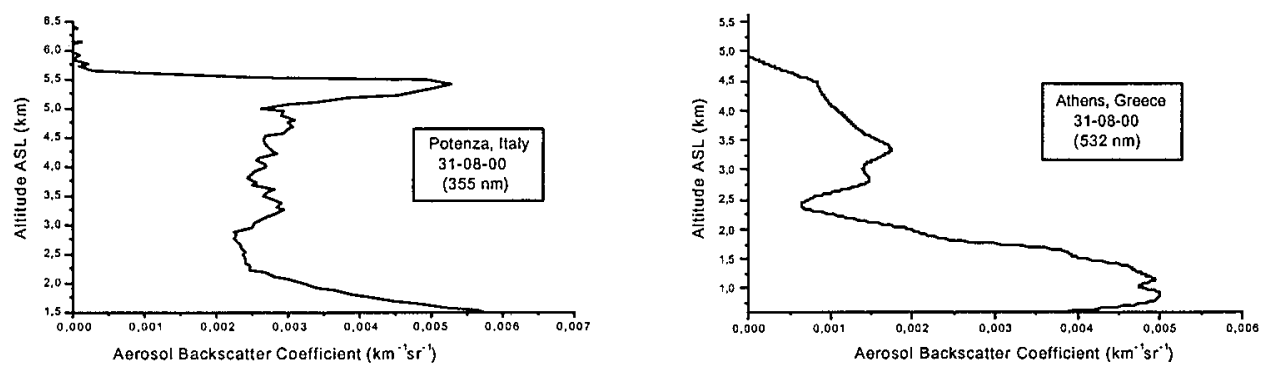

Figure 1. Saharan dust layers observed by lidar simultaneously at 19:00 UT over Potenza (left), Italy at $355 \mathrm{~nm}$ and over Athens (right), Greece at $532 \mathrm{~nm}$, on August 31, 2000.
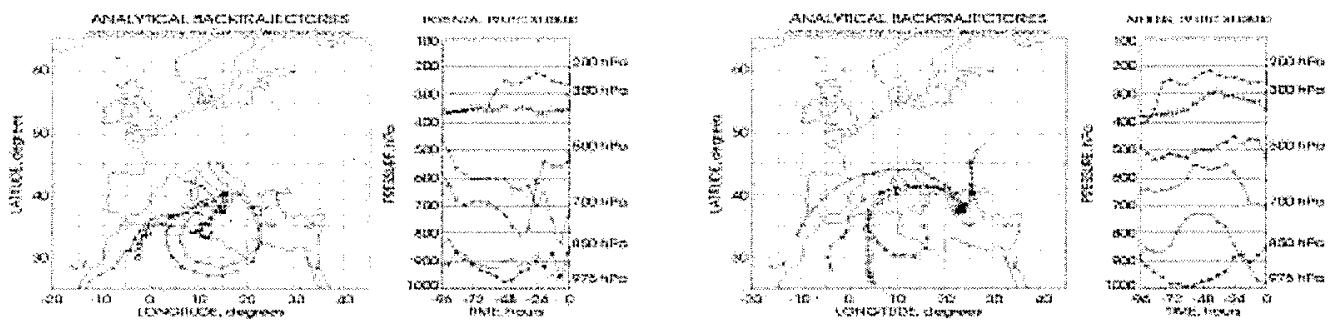

Figure 2: Air-mass back-trajectories ending on August 31, 2000 (19:00 UT) over Potenza, Italy (left) and over Athens, Greece (right).

Similar observations were made over the Western, Central and Eastern Europe, where intense aerosol layers were observed in the $3-7 \mathrm{~km}$ altitude range, all dust layers having their origin in the Sahara region. Aerosol optical depth, spectral radiance and satellite observations (TOMS, METEOSAT, AVHRR) verified the lidar observations and confirmed the horizontal extent of the Saharan dust layers over Europe.

\section{CONCLUSIONS}

The analysis of the data collected, enabled us to observe for the first time, simultaneously the horizontal and vertical extent of free tropospheric Saharan dust layers over Europe, over a time period of six months. The data set collected will be used to improve global and regional atmospheric and radiative transfer models, as well as the METEOSAT inversion procedures.

\section{ACKNOWLEDGEMENTS}

This work was supported by the Environment Program of the European Union, under contract EVR1CT1999-40003. Air-mass trajectory analysis was performed by the German Weather Service (DWD).

\section{REFERENCES}

Dulac, F., D. Tanre, G. Bergametti, P. Buat-Menard, M. Desbois, and D. Sutton, (1992). Assessment of the African airborne dust mass over the Western Mediterranean Sea using Meteosat data, J. Geophysical Research,97, 2489.

Gobbi, G.P., F. Barnaba, R. Giorgi, and A. Santacasa (2000). Altitude-resolved properties of a Saharan dust event over the Mediterranean, Atmospheric Environment 34, 5119.

Hamonou, E., P. Chazette, D. Balis, F. Dulac, X. Schneider, \&. Galani, G. Ancellet, and A. Papayannis (1999). Characterization of the vertical structure of Saharan dust export to the Mediterranean basin, J. Geophysical Research, D104, 22257.

Jaeger, H., W. Carnuth, and B. Georgi (1988). Observation of Saharan dust over a north Alpine mountain station, $J$. Aerosol Sciences 7, 1235.

Seinfeld, J.H. and S.N. Pandis (1998). Atmospheric Chemistry and Physics: From Air Pollution to Climate Change, (J. Wiley and Sons Inc., NewYork, USA). 